Portland State University

PDXScholar

$12-15-2021$

\title{
An Investigation into the Relationship between Obstetric Racism and Postpartum Depression in Black Women
}

Miguel A. Claxton III

Portland State University

Follow this and additional works at: https://pdxscholar.library.pdx.edu/honorstheses

Part of the African American Studies Commons, Ethnic Studies Commons, Medical Humanities Commons, Psychiatric and Mental Health Commons, and the Social and Cultural Anthropology Commons Let us know how access to this document benefits you.

\section{Recommended Citation}

Claxton, Miguel A. III, "An Investigation into the Relationship between Obstetric Racism and Postpartum Depression in Black Women" (2021). University Honors Theses. Paper 1159.

https://doi.org/10.15760/honors.1185

This Thesis is brought to you for free and open access. It has been accepted for inclusion in University Honors Theses by an authorized administrator of PDXScholar. Please contact us if we can make this document more accessible: pdxscholar@pdx.edu. 
An Investigation into the Relationship between Obstetric Racism and Postpartum Depression in Black Women

by

Miguel A. Claxton III

An undergraduate honors thesis submitted in partial fulfillment of the requirements for the degree of

Bachelor of Arts

in

University Honors

and

Anthropology

Thesis Adviser

Dr. Charles Klein

Portland State University 


\section{Introduction and Theoretical Overview}

In the United States of America, the experience of childbirth is highly stratified along axes of race, class, and education level. Of these intersections, the racial stratification of birth outcomes presents itself as particularly alarming, with disparities persisting even when differences in income and education level are accounted for (Tanner et. al., 2018). To understand the current racial inequities of the birth experience in the U.S., it is necessary to understand the historical context of Black birth in relation to paradigms of medico-legal control. Black birth in the United States of America has been shaped by the system of chattle slavery, ideologies of eugenics in the 20th century, and contemporarily by systemic racism. Each of these ideologies has their underpinnings in White supremacy, and have shaped and constructed not only the reproductive lives of Black women, but also the practice of gynecology itself.

Perhaps the starkest example of the racial disparity within obstetrics are the increased rates of pregnancy-related mortality for Black women. Black women's pregnancy-related mortality rate is three to four times higher than that of White women (Cooper Owens, 2019). In addition to higher rates of infant mortality, Black women also have higher rates of other birth complications,"African American women have about a 60\% higher rate of preterm birth and an $88 \%$ higher rate of low birth weight infants than Caucasian women" (Martin et. al., 2011). It is important to note that these statistical differences are correlated with race, however they are not caused by race. In other words, the disparities we see are the result of the social processes of racialization and marginalization, not biological variation. What then, are the social processes that 
marginalize Black birth, and how do these social processes manifest themselves biologically?

Of particular concern are the complications that coincide with a low birth weight, specifically postpartum depression. There is a statistically significant correlation between infants being born with a low birth weight, and the development of postpartum depression, mothers of infants with low birth weight experience higher levels of depressive symptoms during the first postpartum year (Vigod et. al., 2010). While literature on the effect of low birth weight and postpartum depression is sparse, even less has been said on the connection of Black women's increased rates of low birth weight—and what implications that has on the prevalence of postpartum depression for this group.

This paper aims to situate postpartum depression in Black women as a psychological response to the systemic matrix of medico-legal mistreatment they experience. This is not to say that postpartum depression is the result of discrimination, but rather that discrimination can predispose a patient to adverse birth outcomes, and thus higher rates of postpartum depression. Postpartum depression can result in a suite of complications following birth, such as, "a lack of bonding with the baby or feeling very anxious about the baby, lack of appetite, feelings of being a bad mother, fear of harming oneself or the baby, crying for 'no reason', and feeling hopeless, worthless, or sad" (American Psychological Association, 2007). Postpartum depression is reported by nearly $13 \%$ of mothers, making it the most common postpartum mood disorder (Maxwell et. al., 2019).

Since low birth weight coindexes with symptoms of postpartum depression, we can begin by interrogating the possible reasons why Black women have $88 \%$ higher rates of low 
infant birth weight than White women. To understand the disparities that exist between the experiences of racialized Black and White women, it is necessary to use frameworks which acknowledge the historical context and material conditions of the Black birthing experience, from chattle slavery, to the racist stigmas and signified meanings of Black birth and motherhood today. Three frameworks will be used to contextualize the Black birthing experience, each emphasizing the limited options that Black women often find themselves with, navigating a birth system that was not always designed to care for them.

Stratified reproduction describes the matrix of sociocultural incentives and disincentives that frame the reproductive experience. In 1986, Shellee Colen theorized the concept of stratified reproduction to describe the different signified meanings of reproduction based on the sociological position of the mother. The theory encompasses how hegemonic ideas of "good" and "bad" motherhood stigmatize marginalized births, and how material conditions restrict reproductive choice, giving more and better options to those who can afford them (Greil et. al., 2011). This framework allows us to examine the ways in which reproduction is implicitly encouraged or discouraged within a given society, and what implications these have on the birth experience. For example, a 2008-2009 self-administered questionnaire of $1,800 \mathrm{OB} / \mathrm{GYN}$ physicians found that, "providers report that they communicate different options regarding available contraceptive methods based on race, ethnicity, and income" (Garcia, 2015) (Lawrence et. al., 2011). Limited sets of options are often presented to non-White patients based on provider's assumptions of limited education, financial situation, or insurance type. The ways in which reproduction is stratified can be explicit, as in physicians withholding relevant information, or systemic such as medicaid's lack of coverage for IVF. 
Using stratified reproduction, we can see how the system of chattle slavery created an intrinsic relationship between enslaved Black women's reproduction and the economic system of the United States. The continuation of slavery, especially after the transatlantic slave trade was made illegal in 1808 , was dependant on the forced reproduction of enslaved Black women. The United States' dependence on this forced reproduction meant that there was an underlying economic incentive to facilitate Black birth. This fundamental relation on a broad societal level incentivized enslavers to prioritize the maximization of enslaved reproductive capacity, and disincentivize infant death. The disparity between Black and White infant deaths today is greater than it was under antebellum slavery. "Historical demographers estimate that, in 1850, enslaved infants died before 1 year of age at a rate 1.6 times higher than that of white infants (340 vs 217 deaths per 1000 live births). In comparison, CDC figures from 2016 show that today non-Hispanic Black infant mortality is 2.3 times higher than mortality among non-Hispanic White babies (11.4 deaths and 4.9 deaths, respectively)" (Cooper Owens, 2019).

Hegemonic narratives of the fertility of Black women have, since the abolition of slavery-- and thus the reconfiguration of the relationship of Black reproduction and economy, strongly disincentivized reproduction in Black women. One need not look further than Ronald Regan's invocation and creation of 'the welfare queen' to see a succinct example of stratifying reproduction by stigmatizing a certain type of motherhood. The constructions of 'welfare queen' and later, 'anchor baby' are just two examples of the embedded meanings placed on reproduction and the marginalized body. These narratives marginalize these women by positioning their reproductive capacity as a threat to the cohesion of the social fabric and economy of America. 
Stratified reproduction allows us to conceptualize how the fertility and childbearing of Black women are not valued equally to those of affluent White women, "this is evident in a range of practices and policies, including Black women's treatment during slavery, the removal of Native children to off-reservation boarding schools, and coercive sterilizations of poor White women and women of color" (Rutgers, 2014). The explanatory power of stratified reproduction comes in its analysis of how social position influences the way in which a pregnancy may be received, what care one has access to, and the quality of that care. The theory outlines how being racialized, or any other marginalization, interacts with reproduction in a way which limits or incentivizes the reproductive experience.

The second theoretical lens that will be used in understanding the experience of Black birth is necropolitics, theorized by Achille Mbembe. The concept of necropolitics is central to the expression and systematization of racism, as necropolitics is concerned with not only who may be subject to violence but whose death is permissible. In order to understand modern racist violence as it pertains to Black birth in the United States, we must first understand this racism as a function of eugenics, under a larger framework of colonial violence. "The colonial branch of eugenics embraced a theory and practice concerned with the vulnerabilities of white rule and new measures to safeguard European superiority. Designed to control the procreation of the "unfit" lower orders, eugenics targeted "the poor, the colonized" (Stoler, 1989). According to necropolitics, the fundamental aspect of sovereignty is to dictate who lives and who dies, therefore to kill and to allow to live are the limits of sovereignty. We can then categorize racism as a form of biopolitics, a politics that is concerned with the management of bodies that implements necropolitical logic. "In the economy of biopower, the function of racism is to regulate the 
distribution of death and to make possible the murderous functions of the state" (Mbembe 2003).

For Mbembe, the colony is a state of exception, where the sovereign suspends rule of law in the name of public good. In other words, the state creates a jurisdiction where ethics of liberal governmentality are suspended and state violence is wielded with impunity, allowing the state to use its monopoly of violence to the maximum capacity. In late stage colonialism the marginalized body becomes the site of this violence, detached from the spatial constraints of colonial jurisdiction. Mbembe describes the fundamental act of sovereignty as being able to dictate who lives and who dies, this power which we often solely attribute to the state, is also present in the hospital. As Foucault states in Discipline and Punish, the architectural mechanism of the prison, one that aids in the order of bodies, surveillance, and atomization, is also found in the hospital. Mbembe expands upon these parallels by showing that necropolitical modes of thought are also not limited to institutions that are explicitly carceral, but also institutions made in the image of carcerality.

An example of necropolitics as it relates to Black reproduction is the practice of forced sterilization, and eugenics as a broader social movement. In the early 20th century, policies of eugenics in America were systematized, with three states having eugenics boards. These boards were tasked with approving state-sanctioned sterilizations, mainly of people who's reproduction was seen as a threat to a standard of purity defined in opposition to the racialized body. "More than half of the 50 states passed laws permitting the sterilization of people diagnosed with a mental illness, disabled persons, criminals, Native Americans and African Americans" (Patel 2017). 
It is important to understand eugenics as a necropolitical endeavor. As eugenics is concerned with the ordering of the body it is inherently biopolitical (Foucault 2010). It is characterized by a lack of distinction between the arenas of the personal corporal and public political. "One of the essential characteristics of modern biopolitics is the constant need to redefine the threshold in life that distinguishes and separates what is inside and what is outside (Agamben 1998:131). What makes eugenics necropolitical is the ordered permission death.

The final theoretical framework that will be used to understand the birth experience is Obstetric racism. The term 'obstetric racism' was first coined by Dr. Dána-Ain Davis to describe the intersection of obstetric violence and medical racism. The term arose out of a need to describe the experience of obstetric violence on the racialized Black body. While stratified reproduction is a tool which describes ways that pregnancies are both implicitly stigmatized and privileged along metrics of class, race, gender, age; obstetric racism is specifically oriented toward analysing how the process of racialization negatively impacts obstetric care. As obstetric racism is a description of the violence at the intersection of being both racialized and gendered, it is important to deconstruct the term into its constituent parts.

Obstetric violence is, "a form of gender-based violence experienced by people giving birth who are subjected to acts of violence that result in their being subordinated because they are obstetric patients" (Davis, 2019). As most people who give birth identify as women, it is also important to situate obstetric violence within broader frameworks of violent patriarchy. Examples of obstetric violence include violations of autonomy during the labor and delivery process, birth rape, or dehumanizing treatment on the basis of 
pregnancy. Obstetric violence also operates systemically by unnecessarily medicalizing the birth process, with the rate of unnecessary medical intervention rising since 1985 (Sadler et. al., 2016).

Medical racism describes when a medical practitioner delivers substandard care, limits treatment, or withholds medical information from a patient on the basis of race. The most obvious and consequential example of medical racism were the medical practices of doctors under chattle slavery, most notibly J. Marion Sims. Sims, often called the 'Father of Modern Gynecology', developed a surgical treatment for vesico-vaginal fistula by operating on enslaved Black women. Said Sims, "then I made this proposition to the owners of the negroes: 'If you will give me Anarcha and Betsey, I agree to perform no experiment or operation on either of them to endanger their lives, and will not charge a cent for keeping them, but you must pay their taxes and clothe them" (Sims, 1884). The treatment of the enslaved women, named Anarcha, Betsey and Lucy, under Sims was extreme, "under Sims, each woman underwent up to 30 operations over 4 years, allowing him to refine his technique. They were provided no anesthetics" (Wailoo, 2018).

Medical experimentation on the Black body is by no means limited to the field of Gynecology, “Enslaved Black people's bodies were exploited for the development of some aspects of US medical education in the 19th century. Medical schools relied on enslaved Black bodies as 'anatomical material' and recruited students in southern states by advertising its abundance." (Ayah et al., 2020). The legacy of medical experimentation on the Black body persists, through the stereotype of the 'superbody' the false idea that Black people can not, or do not, feel physical pain in the same manner as White persons. This notion served as a justification for medical experimentation in the past, but has had a 
lasting impact on ideas about pain and race within the medical community, resulting in the pain of Black people being systematically under diagnosed, and under treated (Anderson et. al., 2009; Greene et. al., 2003). Using these frameworks to understand the Black birthing experience allows us to contextualize the disparity in birth outcomes that these women face. The higher rates of adverse birth outcomes for Black women do not occur simply because of their race, but because of the legacy of racist medical systems, broader social stigmatization of Black motherhood, and lack of safety in medical institutions.

Given the added stress and anxiety on Black mothers, can a link be made from obstetric racism, low birth weight, and the development of postpartum depression? While it has been established that birth outcomes and postpartum psychological state are linked (Poehlmann et. al., 2009), there has been little study into the racial dimensions of the postpartum psychological state. "Surprisingly little is known about the extent to which postpartum depression varies by race and ethnicity, this dearth of information on postpartum depression in ethnic minorities is well recognized" (Liu and Tronick 2013).

\section{Methods}

The guiding ethos of this investigation is a Black feminist approach, one where knowlege is produced through participants reflecting upon their birthing and pregnancy experiences (Collins, 2000). As Black women inhabit a multitude of marginalized identities, their stories will be situated as the basis for knowledge production in critically analyzing the systems which marginalize them (Davis, 2019). Black feminist thought has its origins in how Black women (like many opressed groups) have interperated their own experience of the world, creating alternative ways of producing and validating knowledge."Black women's political and economic status provides them with a distinctive set of experiences that offers 
a different view of material reality than that available to other groups" (Collins, 1989). The phenomenological experience of marginalization creates a reality that is inaccessible to members of the dominating group, positioning Black women as experts of their experiences.

Interview participants were solicited via ads on Instagram, a social media platform popular with the age demographic of study. Black women over the age of eighteen who were pregnant, or had been so within 8 months, were offered $\$ 50$ in exchange for an hour-long digital interview. This interview aimed to gain an insight on the participant's pregnancies and birth experiences, as well as the experience of maternity-related healthcare. Participants were informed that their answers would be anonymized, and that they could skip questions or terminate the interview at any time without forfeiting monetary compensation.

6 hour-long digital interviews were conducted with Black women who were at the time pregnant, or had given birth within the last 8 months. Participants who were currently pregnant were interviewed to gain an insight into the quality of treatment of Black women during pregnancy, a factor which is important for birth weight outcomes, as well as the psychological state of women going into birth. Women who had given birth within the last eight months were interviewed, as 8 months is considered to be the end of the postpartum period. Each interview focused on the phenomenological experience of obstetric care and the postpartum period (if applicable). Participants were asked to describe their experiences with medical staff, about their pregnancy-related anxieties, and their motivations behind their medical choices. These interviews were then transcribed and cross referenced against each other to see if any common themes emerged. 
Questions Posed to Participants

1. Are you currently pregnant?

2. Do you have insurance?

3. How has the experience of pregnancy (and childbirth) related care been for you?

4. What kind of birth are you planning on having at home? At a hospital?

5. Do you have any birth assistants such as a midwife or doula?

6. What factors did you consider when choosing medical providers?

7. Why are these factors important to you?

8. Can you describe how you feel in the months prior to (and post) birth?

9. Do you feel like your concerns were listened to by medical staff?

10 . Do you have any anxieties surrounding your childbirth experience

11. Do you think you received an acceptable level of care from providers throughout your pregnancy?

12. How do you feel about the medical field in general? Why?

13. What were the outstanding sources of stress throughout your pregnancy (and childbirth)?

Responses were analyzed utilizing Kimberle Crenshaw's theory of intersectionality, which argues that each social position a person occupies, and the ways that those positions are dominant or marginalized, interact in a way which informs experiences of oppression (Crenshaw, 1989). Since obstetric racism is at the intersection of both gender and race, they necessarily inform each other to form a nested set of interdependent experiences of being. Crenshaw notes that gender and race are often treated as mutually exclusive modes of analysis, however this systemically erases the experiences of Black women. Responses were also used to gain a phenomenological understanding of the experience of Black pregnancy. Adjectives pertaining to respondents' emotions were highlighted to visually display the general feelings they had of their experiences.

Results

\begin{tabular}{|l|l|l|l|l|}
\hline Pseudonym & $\begin{array}{l}\text { Location: } \\
\text { Urban/Rural }\end{array}$ & $\begin{array}{l}\text { Insurance: } \\
\text { Private/Public }\end{array}$ & $\begin{array}{l}\text { Pregnant/ } \\
\text { Postpartum }\end{array}$ & $\begin{array}{l}\text { Age Range: } \\
(18-25)(26-32) \\
(33-39)\end{array}$ \\
\hline
\end{tabular}




\begin{tabular}{|l|l|l|l|l|}
\hline Dominique & Urban & Public & Pregnant & $26-32$ \\
\hline Denise & Rural & Private & Postpartum & $18-25$ \\
\hline Gabby & Rural & Public & Postpartum & $36-32$ \\
\hline Renee & Rural & Public & Postpartum & $18-25$ \\
\hline Tyra & Urban & Public & Pregnant & $26-32$ \\
\hline Angelina & Urban & Private & Pregnant & $33-39$ \\
\hline
\end{tabular}

Six Interviews were conducted, three with women who were pregnant at the time of the interview, and three with women who had recently given birth. Three respondents were from urban contexts, major metropolitan cities, and rural, which for the purposes of this study is defined as any location that is not a city. All names are pseudonyms to protect the anonymity of participants. Participants represented a variety of economic contexts being insured both privately and publicly. Participants represented a variety of educational backgrounds from secondary degrees to some college education. Significant sources of stress (a contributing factor to adverse birth outcomes) were identified as a result of being a racialized Black woman in the medical system. Throughout the interviews 4 main themes emerged, each presenting themselves in a variety of contexts. These themes were; isolation, prior knowledge, fear, and community construction.

\section{Isolation}

The theme of isolation in regard to being the only person of color in medical spaces presented itself multiple times. A medical provider's race was never explicitly asked for, but was often provided by participants without prompting, suggesting that it is a salient detail. Usually, participants noted a lack of Black representation in professional medical spaces, indicating that it was a major source of alienation during the birth process. Feelings of 
mistrust for medical institutions in general also contributed to feelings of isolation, with respondents often recounting personal experiences of medical mistreatment prior to pregnancy. The preexisting mistrust of the medical community as well as the alienation felt in all-white spaces constituted a significant source of stress for respondents.

Participant 1 Dominique has a 5 year old son, and was 4 months pregnant with her second child at the time of the interview. She is single, lives in the Portland metro area, and is insured by the Oregon Health Plan. During the interview she stressed how alienating her first birth was, "I've given birth previously and there were no people of color, no Black medical professionals in the room and as a Black woman, I feel uncomfortable when that happens in professional spaces or medical spaces, like situations where I'm vulnerable, and I think that having someone who can advocate for me and just kinda like know what is important to me that's valuable." (Claxton interview 2, 2021)

In her response, Dominique contrasts the experience of her first birth with the experience she hopes to have in the future. She identifies childbirth as a situation where she is vulnerable, and notes that being the only Black person in these vulnerable situations is uncomfortable. The issue of representation in the medical field is one of critical importance to Black women. Far from being superficial, the presence of Black women, Black people, and POC in medical spaces is an indication of institutional safety to Black patients. In her response, Dominique stated that a Black medical professional in the room with her could "advocate for [her]", with it being implied that they could advocate for her better than could a White medical professional. Far from being a superficial variable, a medical provider's race can have broad implications for the care of patients of color. "A study of health services utilization found that when patients were race concordant with 
their physicians, they were more likely to use needed health services, were less likely to postpone or delay seeking care, and they used more health services" (Blanchard et. al., 2007).

Dominique's preference a for race-concordant provider was also shared by other respondents, "I know a lot of Black women have horrible experiences, in pregnancy and childbirth, and, I think that, I think that having a Black doctor, would make it, I don't know, I'd be better taken care of, it would be less likely that there would be complications or problems because... I don't know... someone doesn't care about me" (Claxton interview 1 2021). Dominique's preference for Black medical professionals to be "in the room" is therefore, not an arbitrary preference, but one with major implications for the quality of her birth care. The higher rate of mistrust of White practitioners does not occur in a vacuum, but rather is a self preservation response informed by, "a long history of race-based differential treatment, unequal dissemination of effective medical innovations, and other racist injustices within the medical establishment" (Tekeste et. al. 2018). Institutional mistrust and lack of Black care providers leave Black women, especially those who lack support networks, with few options for support within our medical system.

Prior Knowledge

All participants, whether through personal experience or second hand knowledge, were aware of racial disparities existing in maternal healthcare. The extent of prior knowledge is perhaps a testament to the ubiquity of the problems that Black women face in this arena. The burden of knowing about these oppressive mechanisms is particularly damaging on pregnant women and their unborn children as, "physiologic mechanisms have been hypothesized to link maternal stress to maternal and infant health" (Strutz, 2014). 
Respondents often spoke of their fears that, despite their best efforts in choosing providers that they trust, they would be subject to mistreatment. While prior knowledge of health disparities allowed for respondents to more effectively advocate for themselves, it presented an ever-present reminder that they are in an especially vulnerable position.

Participant 2, Denise, had given birth to a boy 6 months prior to her response, this was her first pregnancy. She is married, and lives in a small town outside of Houston Texas. She has private insurance, and is seeing a therapist for symptoms of postpartum depression. She relayed the story of her friends' poor birth experiences, and described the difficulty in finding medical facilities in her local area that offered adequate levels of care. Finding her local hospital to be lacking, she chose to drive an extra 2 hours to deliver. "Yeah, I mean, I have Black friends that have given birth in [my town] who've experienced all the things I was afraid to [of]. Nurses being rude to them, not caring about them, telling them that 'they don't need XY and Z' when they are asking or saying they have pain, or asking for help in some area I don't know, I just, I didn't want that. I don't know since I've lived in Texas, there are only so many places I feel comfortable at least like I have a shot at being treated like a person, and this is one of them" (Claxton Interview 2, 2021).

Denise's response shows us that even among Black women who have yet to give birth, there is an intimate familiarity with obstetric racism, and violence against Black pregnant women as a category of people. Of note is the example Denise gives of nurses being dismissive of the physical pain of her friends, a phenomena that (as discussed previously) has deep roots in the intersections of Blackness and medicine. Denise's decision to drive an extra two hours to deliver her baby was one that was not taken lightly, the risks 
incurred by such a decision are a testament to just how seriously Denise felt about the treatment she may have been subject to at her local hospital.

Fear

A theme that was interwoven throughout nearly every aspect of pregnancy for the women interviewed was fear. The general fears that one might expect from a parent-to-be, but also fears that are more specific to being marginalized. The fear of mistreatment was pervasive throughout respondent's stated motivations for choosing care providers. While not wholly distinct from prior knowledge, fear was how many respondents relayed their prior knowledge of the birth process. By articulating their fears of medical neglect for example, respondents demonstrate that they know the medical neglect of Black women is something they might face.

Participant 3, named Gabby, had given birth 4 months prior, and is a first time mother. She lives with her partner in a smaller town in the southwest of Oregon, and is insured publically through the Oregon Health Plan. During the interview, Gabby noted that she was afraid of how pregnancy related care would be for her based on prior experiences, "as a Black woman I've felt that um, how can I say, I mean in the past in the own health I've had trouble getting people/doctors to listen to me. I've had doctors kind of um, I don't know yeah I guess my own experiences with my health other than pregnancy kind of you know I'm afraid that might happen during pregnancy, I don't know" (Claxton interview 3 2021). The fear of not being listened to was one that was repeated by multiple respondents. Community Construction

Because of the isolation that is experienced by Black women in our medical system, many of the respondents had taken additional steps to build a community of support 
around themselves. This was achieved via a variety of strategies including, seeking the assistance of doulas and midwives, selecting care providers that share racial/cultural backgrounds, and peer to peer networking. Of these strategies, seeking the assistance of birth workers was seen by respondents as the most impactful. The presence of a doula has the potential to mitigate many adverse outcomes for new mothers, "a 2017 Cochrane review concluded that women who were attended by doulas had fewer cesareans and instrumental births, less pain medication, and more satisfaction with their birth experience" (Sperlich et. al., 2019). It is hardly surprising then that 4 out of 6 respondents had used the services of, or were actively seeking out, a doula.

Participant 4, Renee had given birth to a baby girl 6 months prior to the time of the interview. She lives with her husband in a town outside of Raleigh, North Carolina. This is her first birth, and she made the decision early on in her pregnancy to seek the assistance of a doula. "I had a doula, she's actually provided through my insurance I was able to [UNCLEAR] She is my doula, but also she's still involved with my family though the Healthy Families Program, she's Afro-Latina, and she was awesome, so, so I think she was really helpful in helping to advocate for me in the hospital and such" (Claxton Interview 4, 2021). Renee's doula was provided though public insurance, as a part of the doula program that Renee was involved in, she was able to utilize her doula as a postpartum resource as well. Renee continues, "I wanted um to have support um from someone who can like understand what I might be going through and kinda pick up on, if there were any, If there were any microaggressions, or if there was any lack of care, that was clear to us um happening because of my race, so that's kinda why" (Claxton Interview 4, 2021). 
In Renee's explanation of why she wanted a doula, we can see the implementation of community construction as a strategy to mitigate the impact of the earlier themes that were identified: isolation, and fear. Renee stated that a doula that was Afrolatina would be able to "pick up on if there were any microaggressions", mitigating the potential negative effects of racial isolation and alienation. Renee also stated the importance of having an advocate, having "support from someone who understands", here we can see a potential attempt by Renee to ameliorate the fear that she has over the potential for an adverse birthing experience.

\section{Discussion}

It is clear that the dimension of race has been understudied in relation to postpartum depression. While asserting a direct causal link between postpartum depression and racism is beyond the scope of this paper, some claims about their connection can be made. Black women's higher rates of adverse birth outcomes, particularly preterm birth and low birth weight disproportionately predispose them to postpartum depression. Factors that lead Black women to have disproportionately higher adverse birth outcomes, increased stress, lack of access to medical facilities, pollution exposure, are all also factors which also disproportionately impact Black people. Postpartum depression in Black women as a result of these increased rates of adverse birth outcomes can then be understood as a result of racial weathering. Racial weathering describes the adverse health outcomes linked to systemic disenfranchisement on the basis of race (Geronimus et. al., 2006). Black people, "are more likely to experience chronic stress in the form of material hardship, interpersonal discrimination, structural discrimination, ambient stressors, segregated housing, and personal danger" (Forrester et. al., 2019). 
By situating postpartum depression in Black women as an adverse health outcome caused in part by the stresses and anxieties of racial marginalization, targeted recommendations can be made to ameliorate the problem. The presence of a doula, especially one who is race concordant with their patient, has the potential to mitigate feelings of isolation in patients, as well as advocate for them in areas of cultural sensitivity. The formation of a community of support prior to the postpartum period can also mitigate the worst effects of stress and anxiety on expectant mothers. Doulas should then not be seen as auxiliary birth workers, but as having a central role in the emotional wellbeing of new mothers. As such, a doula's services should be covered under public insurance plans and access to them, especially by higher risk groups, should be more widely available.

Healthcare providers should also take efforts to promote racial diversity among their staff, not only as a matter of equity within healthcare establishments internally, but also as a way of creating an inclusive environment for patients. The anxieties that respondents described regarding seeking medical treatment in all-White spaces are not divorced from the broader history of the medical system and the Black body, it is a response rooted in generational trauma. It is necessary to state that representation within the medical industry is not a panacea, and that systemic problems necessarily require systemic solutions. Combating higher rates of adverse birth outcomes for Black mothers would mean addressing disparities in housing, environmental policy, transportation, wealth disparities, among others.

The experience of Black motherhood in the United States today is one that is characterized by the systemic devaluation of Black life in general. The systems that Black mothers find themselves in often fail to care for them, resulting in adverse outcomes. It is 
perhaps then unsurprising that, "Black Americans are significantly more likely than White Americans to mistrust healthcare personnel and the medical system as a whole" (Tekeste et. al., 2018). Of the six respondents, one had been diagnosed with postpartum depression. Each woman interviewed reported that aspects of their pregnancy were made harder by them being a racialized person. Pregnancy and childbirth are of course times of anxiety and stress for all who are pregnant; however, there are aspects of the experience that impact racially marginalized persons in uniquely detrimental ways. Many of the responses regarding provider racial and cultural competence were aimed at discerning the answer to one existential question, 'does this medical provider view me as a full person?' Until this question has been addressed thoroughly by practitioners through demonstrating a comprehensive understanding of the additional birth risks Black mothers face, Black mothers will remain alienated. 


\section{References}

Agamben, Giorgio. Homo Sacer : Sovereign Power and Bare Life. Stanford University Press, 1998.

American Psychological Association (2007). Postpartum depression. Retrieved from https://www.apa.org/pi/women/resources/reports/ postpartum-depression.aspx

Anderson, K. O., Green, C. R., \& Payne, R. (2009). Racial and ethnic disparities in pain: Causes and consequences of unequal care. The Journal of Pain, 10, 1187-1204. http://dx.doi.org/10.1016/j.jpain.2009.10.002

Blanchard, J., Nayar, S., \& Lurie, N. (2007). Patient-Provider and Patient-Staff Racial Concordance and Perceptions of Mistreatment in the Health Care Setting. Journal of General Internal Medicine : JGIM, 22(8), 1184-1189.

Collins, Patricia Hill. "The Social Construction of Black Feminist Thought." Signs: Journal of Women in Culture and Society, vol. 14, no. 4, 1989, pp. 745-773.

Dána-Ain Davis (2019) Obstetric Racism: The Racial Politics of Pregnancy, Labor, and Birthing, Medical Anthropology, 38:7, 560-573, DOI: 10.1080/01459740.2018.1549389

Forrester, S., Jacobs, D., Zmora, R., Schreiner, P., Roger, V., \& Kiefe, C. (2019). Racial differences in weathering and its associations with psychosocial stress: The CARDIA study. SSM - Population Health, 7, 003.

Foucault, Michel. Discipline and Punish : the Birth of the Prison. 1st American ed. Pantheon Books, 1977.

Foucault, Michel, et al. The Birth of Biopolitics : Lectures at the College De France, 1978-1979. 1st Picador pbk ed., Picador, 2010.

Garcia, Ginny, PhD, et al. "Trends and Disparities in Postpartum Sterilization after Cesarean Section, 2000 through 2008." Women's Health Issues, vol. 25, no. 6, 2015, pp. 634-640.

Geronimus, A., Hicken, M., Keene, D., \& Bound, J. (2006). "Weathering" and Age Patterns of Allostatic Load Scores Among Blacks and Whites in the United States. American Journal of Public Health (1971),96(5), 826-833. 
Greil, Arthur L., et al. "Race-Ethnicity and Medical Services for Infertility: Stratified Reproduction in a Population-Based Sample of U.S. Women." Journal of Health and Social Behavior, vol. 52, no. 4, 2011, pp. 493-509.

Lawrence, R. E., Rasinski, K. A., Yoon, J. D., \& Curlin, F. A. (2011). Factors influencing physicians' advice about female sterilization in USA: A national survey. Human Reproduction, 26(1), 106-111.

Liu, C., \& Tronick, E. (2012). Rates and Predictors of Postpartum Depression by Race and Ethnicity: Results from the 2004 to 2007 New York City PRAMS Survey (Pregnancy Risk Assessment Monitoring System). Maternal and Child Health Journal, 17(9), 1599-1610.

Martin, J. A., Hamilton, B. E., Ventura, S. J.,Osterman, M. J. K., \& Mathews, T. J. (2013).Births: Final data for 2011. National Vital Statistics Reports; Vol. 62, No. 1. Hyattsville, MD: National Center for Health Statistics.

Maxwell, D., Robinson, S., \& Rogers, K. (2019). “I keep it to myself”: A qualitative meta-interpretive synthesis of experiences of postpartum depression among marginalised women. Health \& Social Care in the Community, 27(3), E23-E36

Michelle Sadler, et. al. (2016). Moving beyond disrespect and abuse: addressing the structural dimensions of obstetric violence, Reproductive Health Matters, 24:47, 7-55, DOI: 10.1016/j.rhm.2016.04.002

Moore, S. (2020, September 29). Analysis | ICE is accused of sterilizing detainees. That echoes the U.S.'s long history of forced sterilization. Retrieved November 212020 from https://www.washingtonpost.com/politics/2020/09/25/ice-is-accusedsterilizing-detainees-that-echoes-uss-long-history-forced-sterilization/

Owens, Deirdre Cooper, and Fett, Sharla M. "Black Maternal and Infant Health: Historical Legacies of Slavery." American Journal of Public Health (1971), vol. 109, no. 10, 2019, pp. 1342-1345.

Patel, Priti. "Forced Sterilization of Women as Discrimination." Public Health Reviews, vol. 38, no. 1, 2017, p. 15.

Poehlmann, J., Schwichtenberg, A., Bolt, D., \& Dilworth-Bart, J. (2009). Predictors of Depressive Symptom Trajectories in Mothers of Preterm or Low Birth Weight 
Infants. Journal of Family Psychology, 23(5), 690-704.

Rutgers "Studies from Rutgers State University Yield New Information about Medicare and Medicaid (Stratified Reproduction, Family Planning Care and the Double Edge of History)." Managed Care Weekly Digest, 2014, p. 32.

Sims JM. Story of My Life. New York, NY: D. Appleton \& Co; 1884:236.

Sperlich, M., Gabriel, C., \& St. Vil, N. (2019). Preference, knowledge and utilization of midwives, childbirth education classes and doulas among U.S. black and white women: Implications for pregnancy and childbirth outcomes. Social Work in Health Care, 58(10), 988-1001.

Stoler, Ann L. "Making Empire Respectable: the Politics of Race and Sexual Morality in 20th-Century Colonial Cultures." American Ethnologist, vol. 16, no. 4, 1989, pp. 634-660

Strutz, K., Hogan, V., Siega-Riz, A., Suchindran, C., Halpern, C., \& Hussey, J. (2014). Preconception Stress, Birth Weight, and Birth Weight Disparities Among US Women. American Journal of Public Health (1971),104(8), E125-E132.

Tanner, L. D., Chen, H. Y., Chauhan, S. P., \& Sibai, B. M. (2018). Racial and ethnic disparities in maternal and neonatal morbidities among college educated women, American Journal of Obstetrics \& Gynecology Supplement to January, S558-559.

Tekeste, M., Hull, S., Dovidio, J., Safon, C., Blackstock, O., Taggart, T., ... Calabrese, S. (2018). Differences in Medical Mistrust Between Black and White Women: Implications for Patient-Provider Communication About PrEP. AIDS and Behavior, 23(7), 1737-1748.

Vigod, S., Villegas, L., Dennis, C.-L., \& Ross, L. (2010). Prevalence and risk factors for postpartum depression among women with preterm and low-birth-weight infants: a systematic review. BJOG: an International Journal of Obstetrics and Gynaecology, 117(5), 540-550. https://doi.org/10.1111/j.1471-0528.2009.02493.x

Wailoo, K. (2018). Historical Aspects of Race and Medicine: The Case of J. Marion Sims. JAMA: The Journal of the American Medical Association, 320(15), 1529-1530. 